\title{
BAD overexpression inhibits cell growth and induces apoptosis via mitochondrial-dependent pathway in non-small cell lung cancer
}

Li Jiang ${ }^{1,2 \dagger}$, Man Luo ${ }^{1 \dagger}$, Dan Liư ${ }^{1 \dagger}$, Bojiang Chen ${ }^{1}$, Wen Zhang ${ }^{1}$, Lin Mai ${ }^{1}$, Jing Zeng ${ }^{1}$, Na Huang $^{3}$, Yi Huang ${ }^{4}$, Xianming $\mathrm{Mo}^{5}$ and Weimin $\mathrm{Li}^{1^{*}}$

\begin{abstract}
Background: The pro-apoptotic BCl-2 protein BAD initiated apoptosis in human cells and has been identified as a prognostic marker in non-small cell lung cancer (NSCLC). In this study, we aimed to explore the functions of BAD in NSCLC.

Methods: Overexpression of BAD was performed by transfecting different NSCLC cell lines with wild-type BAD. Cell proliferation, cell cycle, apoptosis, and invasion were characterized in vitro. Tumorigenicity was analyzed in vivo. Western blot was performed to determine the effects of BAD overexpression on the Bcl-2 family proteins and apoptosis-related proteins.

Results: Overexpression of BAD significantly inhibited cell proliferation in H1299, H292, and SPC-A1 but not in SK-MES-1 and H460 cell lines in vitro. BAD overexpression also reduced the tumorigenicity of H1299/SPC-A1 cell in vivo. However, no appreciable effects on cell cycle distribution and invasion were observed in all these cell lines. BAD overexpression also induced apoptosis in all cell types, in which process expression of mitochondrial cytochrom c (cyto-c) and caspase 3 were increased, whereas Bcl-xl, Bcl-2, Bax and caspase 8 expressions did not changed. These findings indicated that a mitochondrial pathway, in which process cyto-c was released from mitochondrial to activate caspase 3, was involved in BAD overexpression-mediated apoptosis.

Conclusions: Our data suggested that increased expression of BAD enhance apoptosis and has negative influence on cell proliferation and tumor growth in NSCLC. Bad is a new potential target for tumor interventions.
\end{abstract}

Keywords: BAD protein, Non-small cell lung cancer, Apoptosis, Cell proliferation, Overexpression

\section{Background}

Lung cancer is the most frequent cancer worldwide with the highest cancer-related mortality [1]. The American Cancer Society estimates that in 2013, there would be 159,480 deaths from lung cancer and 228,190 new cases diagnosed. Of these, non-small cell lung cancer (NSCLC) account for $\sim 85 \%$. Currently therapeutic interventions have little influence on the prognosis of patients with NSCLC. The 5-year survival rates remain less $15 \%$ and recurrence rate still increased after surgery

\footnotetext{
*Correspondence: weimi003@yahoo.com

${ }^{\dagger}$ Equal contributors

'Department of Respiratory Medicine, West China Hospital, Sichuan University, Chengdu 610041, P.R China

Full list of author information is available at the end of the article
}

[2]. Mechanism that enable cancer cell to evade apoptosis may contribute to therapeutic resistance, which is a major challenge for prognostic improvement in NSCLC. Thus, anticancer agents triggered the cell undergoing apoptosis could improve response to treatment and clinical outcome. We recently reported that the $\mathrm{BAD}(\mathrm{Bcl}-\mathrm{Xl} / \mathrm{Bcl}$-2-associated death promoter homologue), as a pro-apoptotic Bcl-2 protein, shows decreased expression level, and plays an important role for predicting therapeutic response and survival in NSCLC [3].

$\mathrm{BAD}$, as one of the "death-promoting" members of the Bcl-2 family [4], is activated through dephosphorylation responsible for apoptotic event, in contrast, inactivation promote cell survival through phosphorylation

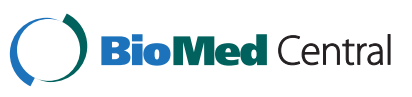


on several serine residues by upstream kinase, such as Akt, Raf, Pim-2, and PKA [3,5]. It is largely assumed that $\mathrm{BAD}$ interact with pro-survival $\mathrm{Bcl}-2$ family proteins, including $\mathrm{Bcl}-2$ and $\mathrm{Bcl}-\mathrm{xl}$, to ablate their pro-survival function. This ablation allows activation of downstream, such as Bax and Bak,to induce cell to apoptosis [6,7]. BAD protein has been reported to contribute to tumorigenesis and chemotherapy resistant. Ranger et al. found that BAD-deficient mice develop diffuse large B cell lymphoma [8]. $\mathrm{BAD}^{-1-}$ mammary cancer cells are resistant to gefitinib-therapy in the study by Gilmore [9]. Moreover, $\mathrm{BAD}$ have been shown to be prognostic biomarkers for colon cancer, ovarian cancer, and breast cancer patients $[10,11]$. Our previous studies also provided clinical evidence that loss of BAD is an independent and powerful predictor of adverse prognosis in NSCLC [3]. Therefore, in addition to regulating apoptosis, BAD might be involved in various cellular functions, such as proliferation and tumor growth in NSCLC.

In this study, our data provided experimental evidence that BAD could play functions as a tumor suppressor in NSCLC. Increased BAD expression has effects on proliferation of NSCLC cell lines and tumor growth in vivo. Meanwhile, BAD overexpression induced apoptosis in all cell types, in which process cytochrom c (cyto-c) and caspase 3 releases was involved.

\section{Methods}

\section{Cell culture and animal models}

The following cell lines were obtained from the Type Culture Collection of the Chinese Academy of Sciences and cultured according to recommendations: NCI-H1299 (metastatic NSCLC, H1299), NCI-H292 (mucoepidermoid adenocarcinoma cell, H292), NCIH460 (large cell carcinoma cells, H460), SPC-A1 (pulmonary adenocarcninoma cells), and SK-MES-1 (squamous cell carcinoma cells, SK-MES). H1299/ H292/H460/SPC-A1/SK-MES-BAD cells (NSCLC cell-BAD) were generated by transfecting those cell lines with wild-type BAD (Pdonr223/BAD, Neuron Biotech, Shanghai, China) as previously described [12]. H1299/H292/H460/SPC-A1/SK-MES-NC cells (NSCLC cell-NC) refer to the cell lines transfected with empty vector (pLOV. UBC. EGFP, Neuron Biotech, Shanghai, China). All cultured cells were maintained in a humidified $5 \% \mathrm{CO} 2$ atmosphere at $37^{\circ} \mathrm{C}$. Nude, 5-8week-old athymic nude mice (BALB/c-nu/nu nude mice), half of which were female and half male were obtained from the Laboratory Animal Centre of Sichuan University. All mice were housed in laminar flow cabinets under specific, pathogen-free conditions with food and water provided ad libitum. All animal procedures listed in this article were performed in accordance with the Helsinki Convention for the use and care of animals, and approved by the Institutional Animal Care and Treatment Committee of Sichuan University.

\section{Tissue protein extraction and western blot assay}

Total protein was extracted from cultured cells and xenograft tumours using the whole protein extraction kit (KeyGEN, Nanjing, China), Protein concentration were measured using BCA Protein Assay Reagent (Thermo scientific, Rockford, USA). Equivalent amounts of protein from different samples were subjected to sodium dodecyl sulphate-polyacrylamide gel electrophoresis (SDS-PAGE) using polyvinylidene fluoride (PVDF) membranes (Millipore, Billeraica, USA) to electro blot. The membranes were incubated overnight at $4^{\circ} \mathrm{C}$ with antiBAD monoclonal antibody (\#9292, 1;1000, Cell Signaling Technology, Beverly, USA), Bcl-xl (\#24247, 1:1000, Signalway Antibody, Pearland, USA), Bcl-2 (\#24246, 1:1000, Signalway Antibody), Bax (\#24250, 1:1000, Signalway Antibody), Caspase 3 (\#21420, 1:1000, Signalway Antibody), Caspase 8 (\#21421, 1:1000, Signalway Antibody), cytochrome C (\#21680, 1:1000, Signalway Antibody) and $\beta$ actin (\#4970, 1:5000, Cell Signaling Technology). Target proteins were detected using the ChemiDoc XRS system (Bio-rad, Philadelphia, USA) by exposure to chemiluminescent HRP substrate (Millipore, Billerica, USA) and analyzed via Quantity One 1-D Analysis software (Bio-rad) $[3,13]$.

\section{Cell proliferation assay}

The effects of BAD on the proliferation of NSCLC cell lines were determined using Cell Counting kit-8 (CCK-8; Dojindo, Kumamoto, Japan) according to the manufacturer's protocol. Briefly, cells were seeded in 96-well plates at a density of $2 \times 10^{3}$ per well. The plates were incubated at $37^{\circ} \mathrm{C}$ for $1,2,3,4,5$ and 6 days. Then the optical density was measured at $450 \mathrm{~nm}$ to determine cell proliferation index. Results are presented as the mean \pm SD based on at least three independent experiments.

\section{Cell cycle analysis}

Approximately $1 \times 10^{6}$ cells were harvested and washed 3 times with PBS and switch to media containing $0.05 \%$ fetal bovine serum (FBS). Then the cells were resuspended in DNA staining solution [(PI, $50 \mu \mathrm{g} / \mathrm{ml})$, RNase A $(100 \mu \mathrm{g} / \mathrm{ml}))$, and $0.1 \%$ (vol/vol) Triton X-100 in PBS) and incubated at room temperature for $30 \mathrm{~min}$. The DNA content was determined by FACS Calibar Flow Cytometer (Becton-Dickinson, Franklin Lakes, USA). Data were analyzed using CellQuest and Modfit software.

\section{Invasion assay}

The invasion of NSCLC cell lines were measured using the BD BioCoat Tumor Invasion Assay System (BD 
Bioscience) according to the manufacture's protocol. Cell suspensions containing $1 \times 10^{6}$ cells $/ \mathrm{ml}$ were seeded onto the upper chamber with serum free media. DMEM containing $10 \% \mathrm{FBS}$, as a chemoattractant, was then added to the lower chamber. After $48 \mathrm{~h}$ of incubation, the invasive cells on the lower surface of the membrane were stained by dipping the inserts into staining solution for $20 \mathrm{~min}$. The cells were measured by photographing the membrane using a microscope at five random views.

\section{Apoptosis assessment}

Approximately $5 \times 10^{5}$ cells were harvested, washed in PBS and incubated with $5 \mu \mathrm{l}$ Annexin V-APC and 7AAD (KeyGen, Nanjing, China) at room temperature for 5 min. Fluorescence was measured using a FACS Calibar Flow Cytometer. The Annexin V-positive and 7AADnegative cells were regarded as apoptotic.

The TUNEL (terminal deoxynucleotidyl transferasemediated dUTP nick end labeling) assay was performed to detect early stage of DNA fragmentation in apoptotic cells by using a commercial kit (In situ Cell Death Detection kit, TMR red, Roche Diagnostics Limited, Shanghai, China). Paraffin-embedded xenograft tumor sections were permeabilized in $0.1 \%$ Triton X-100, and then incubated with TUNEL reaction mixture containing TdT and TMR-dUTP. During this incubation step, TdT catalyzes the attachment of TMR-dUTP to free 3'OH ends in the DNA. Nuclei were counterstained with DAPI. Tissue sections were analyzed for apoptotic cells with localized TMR red under a fluorescence microscope. The apoptotic cell rate was determined according to the formula: (number of apoptotic cell with red staining/total number tumor cells with DAPI staining) $\times 100 \%$.

\section{Immunohistochemistry}

IHC assay was performed on histological sections of formalin-fixed tumor xenografts as previously described $[3,14]$. The primary antibody is proliferative marker ki-67 (1:100, Dako). The positive cell rate was measured using a microscope at five random views.

\section{Assessment of tumorigenicity in vivo}

All kinds of treated $\mathrm{H} 1299$ and SPC-A1 cells were harvested $\left(1 \times 10^{6}\right.$ cells in $\left.150 \mu \mathrm{l}\right)$ and injected subcutaneously in athymic nude mice. Mice were divided into three groups, including H1299/SPC-A1, H1299/SPC-A1BAD overexpression (H1299/SPC-A1-BAD), and BADnegative control (H1299/SPC-A1-NC). Four weeks later, mice were sacrificed, and tumors were dissected and weighed, then fixed using formalin or stored at $-80^{\circ} \mathrm{C}$ until further use. Tumor volume $\left(\mathrm{mm}^{3}\right)=0.52 \times$ length $(\mathrm{mm}) \times$ width $(\mathrm{mm}) \times$ width $(\mathrm{mm})$. Each group contains 6 mice.

\section{Statistical analysis}

Pearson chi-square tests were used to assess the difference in protein expression status among cell lines and tissues. Analysis of variance was performed to determine the statistical significance of differences among the experimental groups. All values were expressed as means $\pm \mathrm{SD}$, and Levels of statistical significance were set at $\mathrm{P}<0.05$ (two-sided). All data were analyzed using SPSS 13.0 for Windows (SPSS Inc., Chicago, Ill, USA).

\section{Results}

Overexpression of BAD in NSCLC cell lines inhibits cell proliferation in vitro and tumor growth in vivo

To determine whether high levels of BAD expression contributed to the NSCLC cell proliferation, invasion and apoptosis, we employed a BAD-expressing vector Pdonr223/BAD-pLOV. UBC. EGFP to transfect BAD into NSCLC cell lines, including H1299, H292, A549, H460 and SK-MES. As shown in the Figure 1, expression level of BAD drastically increased in transfected cell groups compared with the non-transfected and empty vector-transfeced cell group (all $\mathrm{p}<0.05$ ). In the NC group, BAD expression was not affected by unrelated vector.

Cell proliferation was examined using Cell counting kit-8 at the time points of 1, 2, 3, 4, 5, and 6 days. The cell proliferation rates of the BAD overexpression cell group were significantly decreased compared with $\mathrm{NC}$ and normal cell lines in H292, H1299, and SPC$\mathrm{A} 1$, respectively (Figure $2 \mathrm{~A}-\mathrm{C}$, all $\mathrm{p}<0.01$ ), while showed a trend toward lower proliferation rate in H460 cell line, although the difference did not reach statistical significance (Figure $2 \mathrm{D}, \mathrm{p}=0.077$ ). However, no differences were observed when SK-MES-1 cell

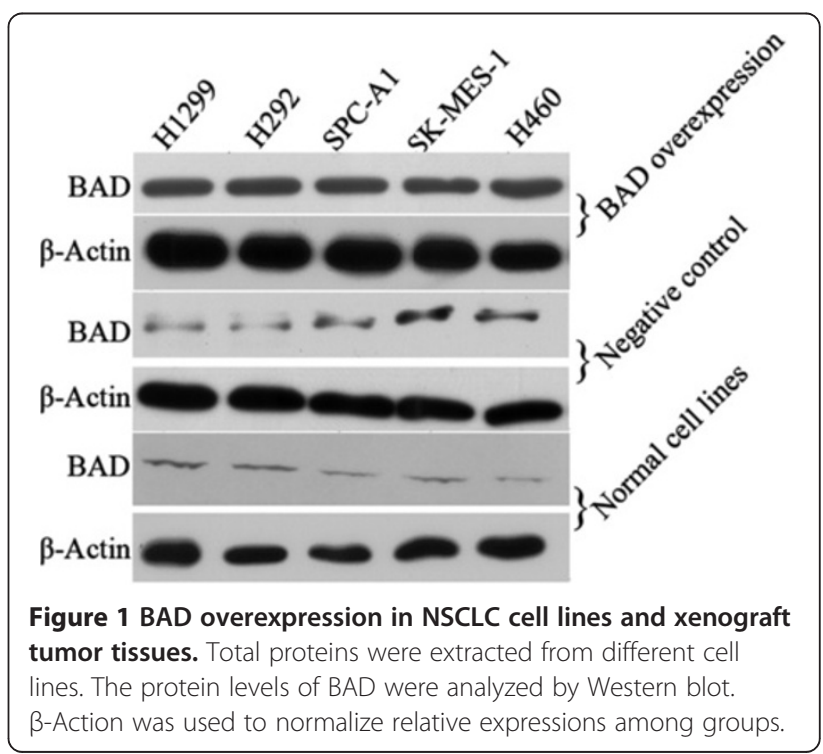




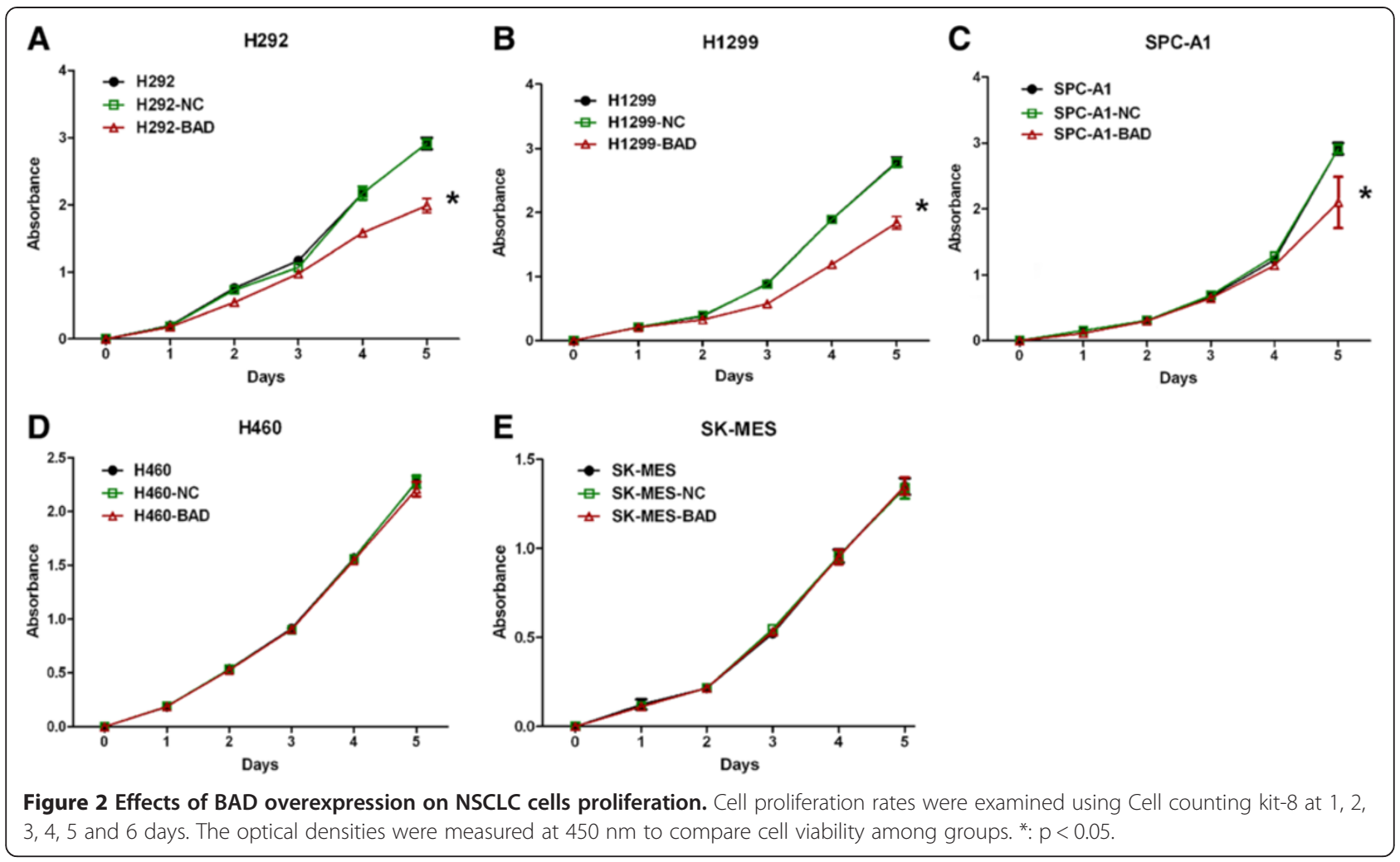

line was transfected (Figure 2E, $\mathrm{p}>0.05)$ ), suggesting that BAD overexpression inhibited cell proliferation except for squamous cancer cell line. In cell cycle analysis, our results demonstrated that no significant effect on the cell cycle distribution was observed in all cell lines (Figure 3, all p >0.05).

To better understand the effects of BAD overexpression on NSCLC, xenograft models were established. After subcutaneous injection of H1299/SPC-A1, H1299/SPC-A1BAD and H1299/SPC-A1-NC cells to the BALB/c-nunu nude mice, tumor volumes were measured every 3 days. Cells in H1299/SPC-A1 and NC group can rapidly form tumors. Nevertheless, BAD overexpression in H1299/ SPC-A1 cells reduced tumor formation compared with H1299/SPC-A1 and H1299/SPC-A1-NC control (Figure 4A-B, all $\mathrm{p}<0.01)$. H\&E staining showed that xenograft tumor tissues retained major features of the original cancer (Figure 4B). In accordance with the slower growth of H1299/SPC-A1-BAD xenograft, immunohistochemical analysis showed less cells that stained positive for the proliferative marker Ki-67 than those of the controls (Figure 4C-D, all $\mathrm{p}<0.01$ ).

\section{Overexpression of BAD has no effect on cell invasion ability}

Cell invasion assays were performed to determine the impact of BAD overexpression in NSCLC. We counted invasive cells that transferred to the lower surface of the membrane at five randomly located areas. In all cell types, BAD overexpression had no influence on cell invasion in NSCLC cell types (data not shown, all >0.05).

\section{Overexpression of BAD induced cell apoptosis in NSCLC cell and xenograft tumors}

Apoptotic rates were determined by flow cytometry and TUNEL assays. Our results showed that overexpression of BAD markedly promoted cell apoptosis. In H1299, H292, H460, SPC-A1, and SK-MES-1 cell lines overexpressing $\mathrm{BAD}$, the average apoptotic rates were $19.42 \%, 23.70 \%, 41.72 \%, 3.92 \%$, and $3.12 \%$, respectively, which were higher than those of the control groups (Figure $5 \mathrm{~A}-\mathrm{B}$, all $<0.05$ ), especially in H460-BAD group $(p=0.000)$.

For the xenograft mice, paraffin-embedded sections of H1299 and SPC-A1 tumor were also subjected to TUNEL assay. As shown in Figure 5D, apoptotic cells showed red staining using an inverted fluorescence microscope. The results indicated that the apoptotic cell rates were higher in H1299-BAD and SPC-A1-BAD groups than the controls by $>2$-fold (Figure $5 \mathrm{C}, \mathrm{p}<0.05$ ). All data suggested BAD overexpression significantly enhanced tumor cell apoptosis. 


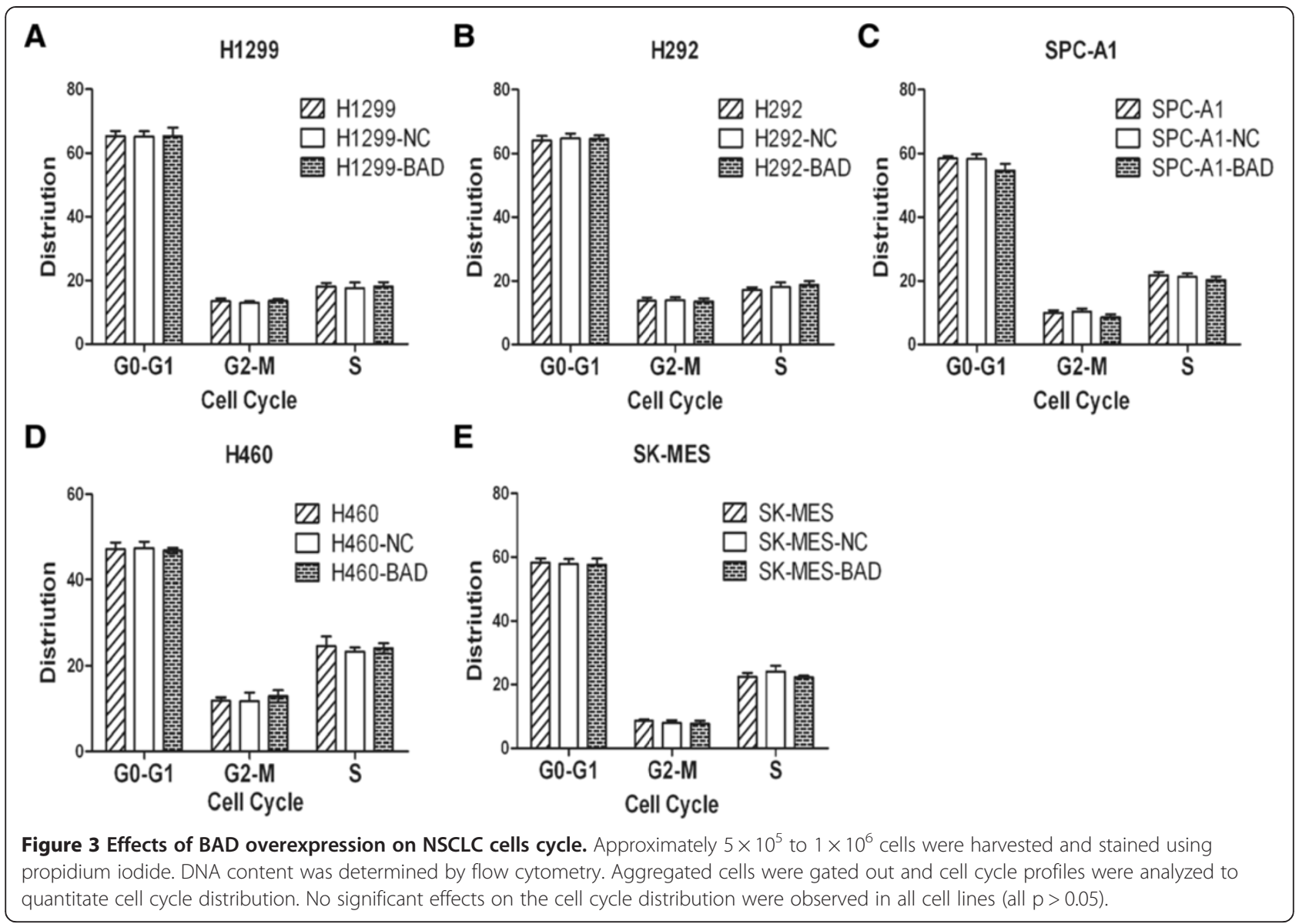

Overexpression of BAD enhanced the cyto-c and caspase 3 expressions

In xenograft tumor tissues, the expression levels of BAD were increased in overexpression groups compared with H1299/SPC-A1 and H1299/SPC-A1-NC cell groups (Figure 6A-B).

As BAD is one of core members of the Bcl-2 family, we further analyzed the effect of BAD on expression of other Bcl-2 family members, including Bcl-xl, Bcl-2, Bax, however, all protein above remained unchanged. Meanwhile, expression levels of apoptosis related proteins, such as cyto-c, caspase-3, and caspase-8, were also determined by western blot. Among the proteins aforementioned, cyto-c and caspase 3 expressions were significantly higher in the BAD overexpression group than the controls (all p < 0.05); whereas the other proteins showed similar expression levels in different groups (Figure 6C-D, all $\mathrm{p}>0.05)$.

\section{Discussion}

$\mathrm{BAD}$, an important regulator of the cell death machinery, has been reported to contribute to tumorigenesis in several cancers $[10,15,16]$. Loss-of-function models of BAD protein are associated with increased incidence of tumors, and over time, BAD-deficient mice show an increased death rate from tumors [17]. In light of these findings, tumor therapy with BAD protein up-regulation may be warranted. In the present study, we demonstrated that up-regulation of BAD significantly reduced cell proliferation in H1299, H292 and SPC-A1 cell lines in vitro and H1299/SPC-A1 cell tumor growth in vivo, but has no appreciable effects on cell cycle distribution and invasion (data not shown, all $\mathrm{p}>0.05)$ in all cell lines. BAD overexpression also induced apoptosis in all cell types, of which process cyto-c and caspase 3 was involved.

BAD protein, as one of cell death initiators, constitutes a critical control point in apoptosis following cellular damage. Loss of BAD expression alone may promote tumorigenesis due to lack of apoptosis and accumulation of cells with tumorigenic potential. In our study, overexpression of BAD was able to greatly increase the apoptotic rates of NSCLC cell in cultured cells and xenograft tissues, confirming its proapoptotic nature. These are keeping with the report by Mork et al. [18] 


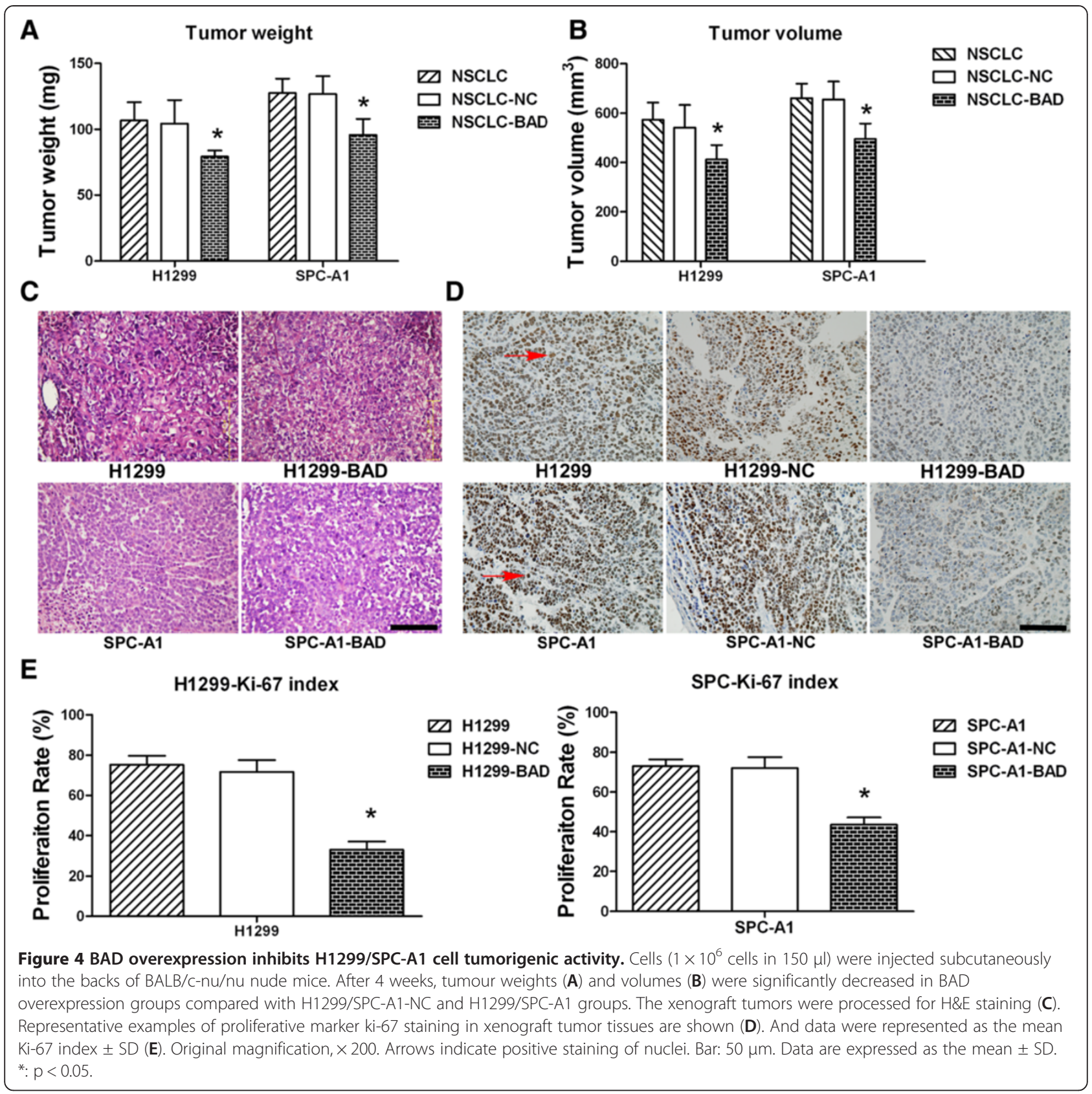

that BAD act as a key regulator of $\mathrm{T}$ cell apoptosis and BAD transgenic mice have depleted numbers of $T$ cells by enhancing sensitive to apoptotic stimuli. Agshin et al. [19] also found that prostatic carcinoma cell line LNCaP, which was resistant to tumor necrosis factor-related apoptosis-inducing ligand (TRAIL)-induced apoptosis, became sensitive to TRAIL and promote apoptotic rate after overexpression of full-length, wild-type BAD. [18]. However, the apoptotic effect of BAD protein overexpression is still controversial. Several studies have shown that overexpression of $\mathrm{BAD}$ alone in a cell line has no effect on apoptosis, whereas coexpressing of $\mathrm{BAD}$ and $\mathrm{Bcl}-\mathrm{xl}$ significantly influence cell apoptosis, suggesting that the action of BAD is dependent on heterodimerization with Bcl-xl $[20,21]$. Thus, we proposed that the effect of $\mathrm{BAD}$ on apoptosis is a result of regulation and interaction with other $\mathrm{Bcl}-2$ family members, including $\mathrm{Bcl}-\mathrm{xl}, \mathrm{Bcl}-2$, and Bax. Unexpectedly, all these protein expression levels were unchanged. These indicated that BAD could function as a powerful regulator of apoptosis in NSCLC cell independent of Bcl-xl/Bcl-2/ Bax interactions or expressions.

Two major apoptotic pathways, the death receptor (extrinsic pathway) and the mitochondrial pathway 


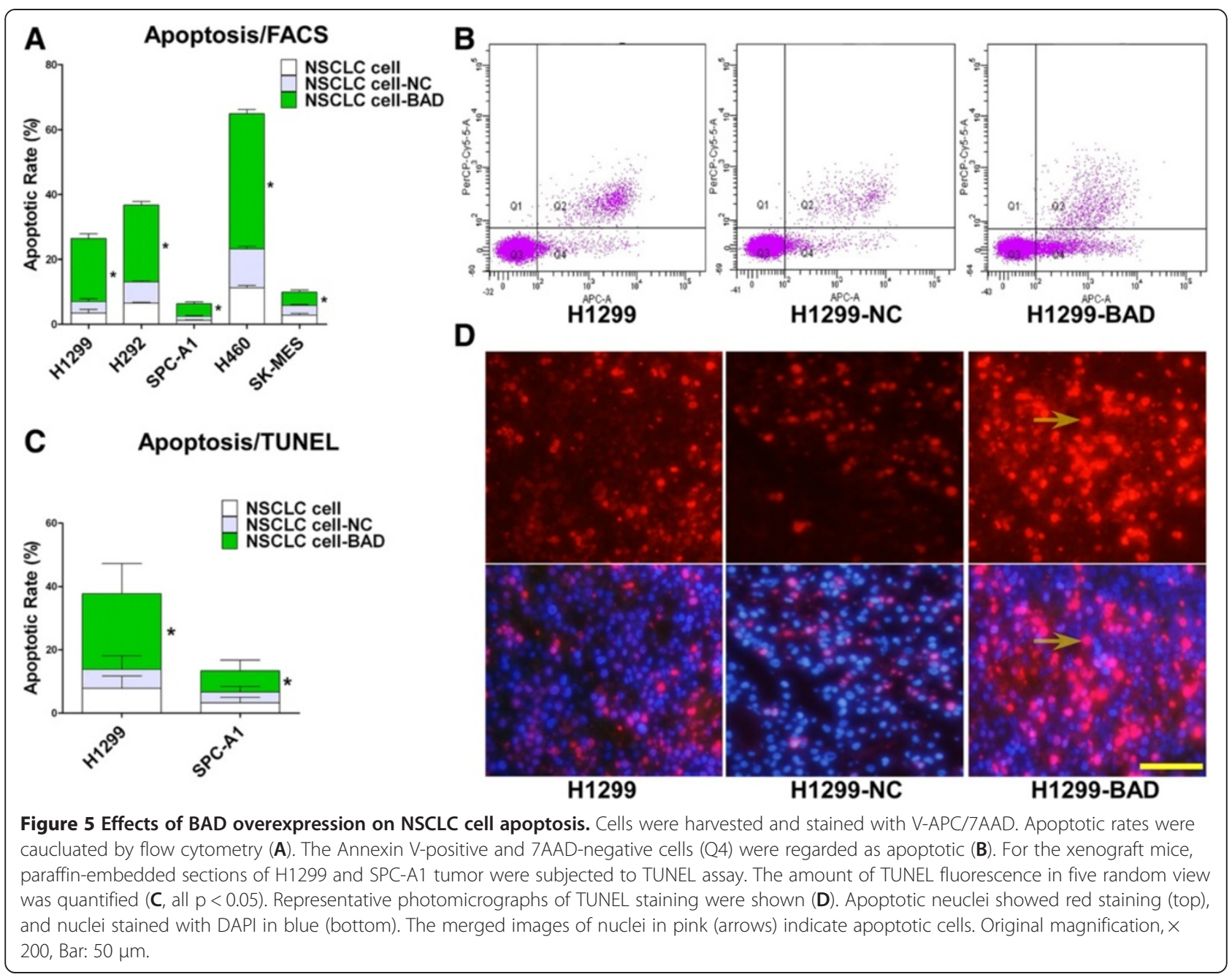

(intrinsic pathway), have been well characterized in mammalian cells. Over the cause of these pathways, activation of the death receptor first triggers caspase8 activation, whereas the release of mitochondrial cyto-c activates caspases-9 as an initial caspase 9, all of which subsequently induced the activation of effectors caspases, such as caspase 3 [22,23]. Cyto-c is an important mitochondrial protein that induces apoptosis when accumulated in the cytosol in response to diverse stress stimuli [24]. In our study, the results revealed that cyto-c and caspase 3 were increased by overexpressing BAD, whereas caspase 8 did not change. These indicated that BAD overexpressioninduced apoptosis is associated with cyto-c releasing from mitochondrial, independent of caspase 8 activation. These are in accordance with the studies by Cheng [25] and Wei [26] that BH3 domain-only molecules, including $\mathrm{BAD}$, were required for the disruption of mitochondrial and intrinsic death of cancer cells [27]. Thus, we suggested that BAD overexpression in
NSCLC led cancer cells to undergo apoptosis through a mitochondrial pathway.

The pro-apoptotic Bcl-2 family proteins Bax and Bak have been shown to be required for the disruption of mitochondrial and intrinsic death of cancer cells, where as the antiapoptotic Bcl-2 family proteins (Bcl-2 and $\mathrm{Bcl}-\mathrm{xl}$ ) can prevent cell death by interfering with the activation of Bax and Bak [22]. In the present study, we found that the expression levels of Bax, Bcl-2 and Bcl-xl were not changed after BAD overexpression. These suggested that the Bad overexpression-induced mitochondrial pathway was independent of $\mathrm{Bax}, \mathrm{Bcl}-2$ and $\mathrm{Bcl}-\mathrm{xl}$ expression levels.

Recent investigations suggest that functions of the proapoptotic protein $\mathrm{BAD}$ are not limited regulating apoptosis [21]. We also found that high level of BAD protein inhibited cell proliferation in H1299, H292, SPC-A1 cell line, and reduced H1299 tumor growth rate in immunocompetent mice. Further immunohistochemical analysis 

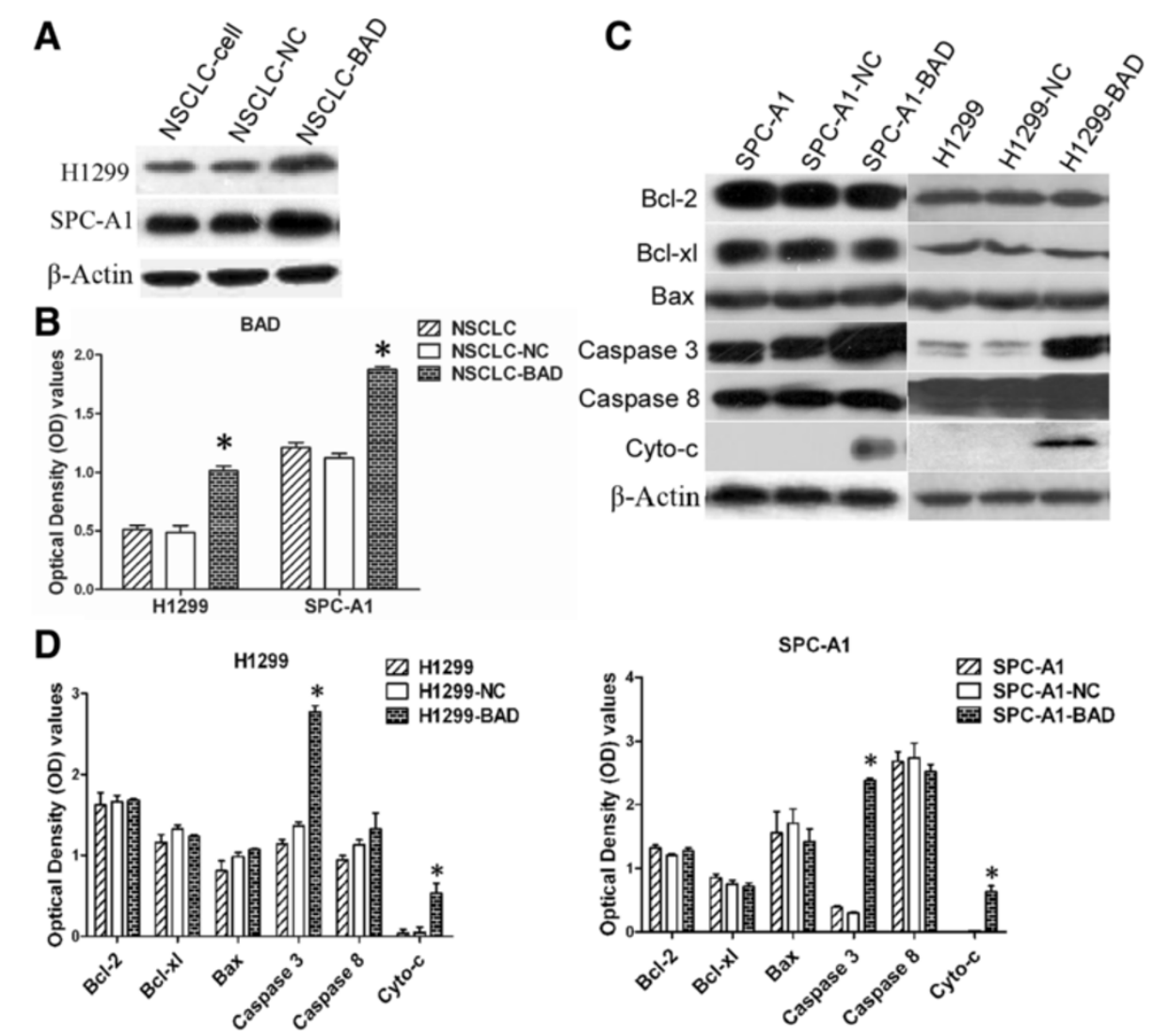

Figure 6 The expressions of $\mathrm{Bcl}-2$ family proteins and apoptotic related proteins after BAD overexpression. Western blot analysis confirmed that BAD were overexpressed in xenograft model (A-B). The expression levels of BCl-2, BCl-xl, Bax, caspase 3, caspase 8 and cyto-c after BAD overexpression were analyzed (C-D, from top to bottom). $\beta$-Actin was used to normalize relative expressions among groups.

showed that xenograft tumor with BAD overexpression had a decreased number of cells that stained positive for the proliferative marker Ki-67. For H460, a large cell lung cancer cell line, the result also showed a trend toward lower proliferation rate, although the difference did not reach statistical significance. All these indicated that BAD play a negative role in specific cell types, especially in adenocarcinoma cells. This is keeping with our previous report that overexpression of BAD suppressed cell proliferation in another lung adenocarcinoma cell line A549 [12]. In breast cancer cell MCF7, cell growth was also inhibited by BAD overexpression [21]. Contradictive reports appeared that increased BAD expression stimulates proliferation of prostate cancer cells [28]. Knockdown of BAD also led to marked inhibition of proliferation in A375 and SK-MEL-28 malignant melanoma cells, and this growth inhibition could be abrogated by overexpression of wild type BAD [29]. Additionally, in our study, no differences of proliferation were observed in SK-MES-1 squamous cell lung cancer cell. These different results indicating that the effect of BAD on cell proliferation may be cell-type-specific.
To further characterize the mechanism underling growth inhibition, we performed cell cycle analysis. Publications from the Vogt and Yang laboratories have suggested that BAD protein can be involved in promoting cell cycle progression in fibroblast $[28,30,31]$. On the contrary, our results showed that overexpression of BAD did not influence cell cycle distribution in all NSCLC cells. These suggested that, in NSCLC, BAD inhibited cell proliferation in vitro and tumor growth in vivo through direct induction of apoptosis without affecting cell cycle progression.

In cell invasion analysis, our data demonstrated that BAD overexpression had no influence on cell invasion in NSCLC cell types. In contrast, a previous AACR symposium poster [32] reported that BAD inhibited cancer cell invasion in breast cancer. From now on, there are very limited reports of the effects of BAD on cell invasion. These inconsistencies remained to be confirmed in expanded and intensive studies.

\section{Conclusions}

In conclusion, this study extended our previous findings that BAD expression level was an independent poor 
prognostic marker in NSCLC patients. BAD overexpression alone induces cell apoptosis, and depressed cell proliferation and cell growth depends on cell types, especially in adenocarcinoma. In the further investigation, BAD may function as tumor suppressor regulating cell growth and apoptosis in the development of NSCLC, and is a potential target for tumor intervention.

\section{Abbreviation \\ NSCLC: Non-small cell lung cancer; cyto-c: Cytochrom c.}

\section{Competing interests}

The authors declare that they have no competing interests.

\section{Authors' contributions}

$J$ and Man LM carried out most of the experimental studies. LD participated in designing the research, performed statistical analyses and drafted the manuscript. CBJ, ZW and ML participated in the animal and cell experiments. ZJ and $\mathrm{HN}$ participated in western blot assays. HY performed statistical analyses and drafted the manuscript. MXM revised the manuscript. LWM designed the research, supervised the experiments and completed the manuscript. All authors read and approved the final manuscript.

\section{Acknowledgments}

This work was supported by grants from the Nature Science Foundation of China (grant 81241068 to WM.L. and grant 81201851 to D.L.) and Sichuan Science and Technology Department (grant 2001SZO 194 and 2011HH0051 to WM.L.).

\section{Author details}

'Department of Respiratory Medicine, West China Hospital, Sichuan University, Chengdu 610041, P.R China. ${ }^{2}$ Department of Respiratory Medicine, Nanchong Central Hospital, Nanchong 637000, P.R China. ${ }^{3}$ Department of Respiratory Medicine, the First Affiliated Hospital of Chengdu Medical College, Chengdu 610072, P.R China. ${ }^{4}$ Clinical Laboratory Department, Sichuan Academy of Medical Sciences and Sichuan Provincial People's Hospital, Chengdu 610072, P.R China. ${ }^{5}$ Laboratory Stem Cell Biology, State Key Laboratory of Biotherapy, West China Hospital, Sichuan University, Chengdu 610041, P.R China.

Received: 20 March 2013 Accepted: 27 May 2013

Published: 1 June 2013

\section{References}

1. Selinger Cl, Cooper WA, Al-Sohaily S, Mladenova DN, Pangon L, Kennedy CW, McCaughan BC, Stirzaker C, Kohonen-Corish MR: Loss of special AT-rich binding protein 1 expression is a marker of poor survival in lung cancer. J Thorac Oncol 2011, 6:1179-1189.

2. Jemal A, Siegel R, Ward E, Hao Y, Xu J, Thun MJ: Cancer statistics, 2009. CA Cancer J Clin 2009, 59:225-249.

3. Huang Y, Liu D, Chen B, Zeng J, Wang L, Zhang S, Mo X, Li W: Loss of Bad expression confers poor prognosis in non-small cell lung cancer. Med Oncol 2012, 29:1648-1655.

4. Downward J: How BAD phosphorylation is good for survival. Nat Cell Biol 1999, 1:E33-E35.

5. Kuroda J, Taniwaki M: Involvement of BH3-only proteins in hematologic malignancies. Crit Rev Oncol Hematol 2009, 71:89-101.

6. Adams JM, Cory S: The BCl-2 apoptotic switch in cancer development and therapy. Oncogene 2007, 26:1324-1337.

7. Sommer P, Cowen RL, Berry A, Cookson A, Telfer BA, Williams KJ, Stratford IJ, Kay P, White A, Ray DW: Glucocorticoid receptor over-expression promotes human small cell lung cancer apoptosis in vivo and thereby slows tumor growth. Endocr Relat Cancer 2010, 17:203-213.

8. Ranger AM, Zha J, Harada H, Datta SR, Danial NN, Gilmore AP, Kutok JL, Le Beau MM, Greenberg ME, Korsmeyer SJ: Bad-deficient mice develop diffuse large B cell lymphoma. Proc Natl Acad Sci U S A 2003 100:9324-9329.

9. Gilmore AP, Valentijn AJ, Wang P, Ranger AM, Bundred N, O'Hare MJ, Wakeling A, Korsmeyer SJ, Streuli CH: Activation of BAD by therapeutic inhibition of epidermal growth factor receptor and transactivation by insulin-like growth factor receptor. J Biol Chem 2002, 277:27643-27650.

10. Sinicrope FA, Rego RL, Foster NR, Thibodeau SN, Alberts SR, Windschitl HE, Sargent DJ: Proapoptotic Bad and Bid protein expression predict survival in stages II and III colon cancers. Clin Cancer Res 2008, 14:4128-4133.

11. Seow HF, Yip WK, Loh HW, Ithnin H, Por P, Rohaizak M: Immunohistochemical detection of phospho-Akt, phospho-BAD, HER2 and oestrogen receptors alpha and beta in Malaysian breast cancer patients. Pathol Oncol Res 2011, 16:239-248.

12. Huang N, Zhu J, Liu D, Li YL, Chen BJ, He YQ, Liu K, Mo XM, Li WM: Overexpression of Bcl-2-associated death inhibits A549 cell growth in vitro and in vivo. Cancer Biother Radiopharm 2012, 27:164-168.

13. Liu D, Huang Y, Zeng J, Chen B, Huang N, Guo N, Liu L, Xu H, Mo X, Li W: Down-regulation of JAK1 by RNA interference inhibits growth of the lung cancer cell line A549 and interferes with the PI3K/mTOR pathway. J Cancer Res Clin Oncol 2011, 137:1629-1640.

14. Liu D, Huang Y, Chen B, Zeng J, Guo N, Zhang S, Liu L, Xu H, Mo X, Li W: Activation of mammalian target of rapamycin pathway confers adverse outcome in nonsmall cell lung carcinoma. Cancer 2011, 117:3763-3773.

15. Al-Bazz YO, Underwood JC, Brown BL, Dobson PR: Prognostic significance of Akt, phospho-Akt and BAD expression in primary breast cancer. Eur J Cancer 2009, 45:694-704.

16. Marchion DC, Cottrill HM, Xiong Y, Chen N, Bicaku E, Fulp WJ, Bansal N, Chon HS, Stickles XB, Kamath SG, Hakam A, Li L, Su D, Moreno C, Judson PL, Berchuck A, Wenham RM, Apte SM, Gonzalez-Bosquet J, Bloom GC, Eschrich SA, Sebti S, Chen DT, Lancaster JM, et al: BAD phosphorylation determines ovarian cancer chemosensitivity and patient survival. Clin Cancer Res 2012, 17:6356-6366.

17. Danial NN: BAD: undertaker by night, candyman by day. Oncogene 2008 , 27(Suppl 1):S53-S70.

18. Mok CL, Gil-Gómez G, Williams O, Coles M, Taga S, Tolaini M, Norton T, Kioussis D, Brady HJ: Bad can act as a key regulator of $\mathrm{T}$ cell apoptosis and T cell development. J Exp Med 1999, 189:575-586.

19. Taghiyev AF, Guseva NV, Harada H, Knudson CM, Rokhlin OW, Cohen MB: Overexpression of BAD potentiates sensitivity to tumor necrosis factorrelated apoptosis-inducing ligand treatment in the prostatic carcinoma cell line LNCaP. Mol Cancer Res 2003, 1:500-507.

20. Yang E, Zha J, Jockel J, Boise LH, Thompson CB, Korsmeyer SJ: Bad, a heterodimeric partner for $\mathrm{BCl}-\mathrm{XL}$ and $\mathrm{BCl}-2$, displaces $\mathrm{Bax}$ and promotes cell death. Cell 1995, 80:285-291.

21. Fernando R, Foster JS, Bible A, Strom A, Pestell RG, Rao M, Saxton A, Baek SJ, Yamaguchi K, Donnell R, et al: Breast cancer cell proliferation is inhibited by BAD: regulation of cyclin D1. J Biol Chem 2007, 282:28864-28873.

22. Lee KW, Kim SG, Kim HP, Kwon E, You J, Choi HJ, Park JH, Kang BC, Im SA, Kim TY, Kim WH, Bang YJ, et al: Enzastaurin, a protein kinase $C$ beta inhibitor, suppresses signaling through the ribosomal $\mathbf{6} 6$ kinase and bad pathways and induces apoptosis in human gastric cancer cells. Cancer Res 2008, 68:1916-1926.

23. Hengartner MO: The biochemistry of apoptosis. Nature 2000, 407:770-776.

24. Chauhan D, Pandey P, Ogata A, Teoh G, Krett N, Halgren R, Rosen S, Kufe D, Kharbanda S, Anderson K: Cytochrome c-dependent and independent induction of apoptosis in multiple myeloma cells. J Biol Chem 1997, 272:29995-29997.

25. Cheng EH, Wei MC, Weiler S, Flavell RA, Mak TW, Lindsten T, Korsmeyer SJ: $\mathrm{BCL}-2, \mathrm{BCL}-\mathrm{X}(\mathrm{L})$ sequester $\mathrm{BH} 3$ domain-only molecules preventing $\mathrm{BAX}$ and BAK-mediated mitochondrial apoptosis. Mol Cell 2001, 8:705-711.

26. Wei MC, Zong WX, Cheng EH, Lindsten T, Panoutsakopoulou V, Ross AJ, Roth KA, MacGregor GR, Thompson CB, Korsmeyer SJ: Proapoptotic BAX and BAK: a requisite gateway to mitochondrial dysfunction and death. Science 2001, 292:727-730.

27. Xiao D, Singh SV: Diallyl trisulfide, a constituent of processed garlic, inactivates Akt to trigger mitochondrial translocation of BAD and caspase-mediated apoptosis in human prostate cancer cells. Carcinogenesis 2006, 27:533-540.

28. Smith AJ, Karpova Y, D'Agostino R Jr, Willingham M, Kulik G Expression of the $\mathrm{BCl}-2$ protein $\mathrm{BAD}$ promotes prostate cancer growth. PLoS One 2009, 4:e6224.

29. Polzien L, Baljuls A, Albrecht M, Hekman M, Rapp UR: BAD contributes to RAF-mediated proliferation and cooperates with B-RAF-V600E in cancer signaling. J Biol Chem 2011, 286:17934-17944. 
30. Maslyar DJ, Aoki M, Vogt PK: The growth-promoting activity of the Bad protein in chicken embryo fibroblasts requires binding to protein 14-3-3. Oncogene 2001, 20:5087-5092.

31. Chattopadhyay A, Chiang CW, Yang E: BAD/BCL-[X(L)] heterodimerization leads to bypass of G0/G1 arrest. Oncogene 2001, 20:4507-4518.

32. Cekanova M, Fernando R, Wimalasena J: P1-02-11: the BCL2 antagonist of death, BAD is down-regulated in breast cancer and inhibits cancer cell invasion. Abstracts: Thirty-Fourth Annual CTRC-AACR San Antonio Breast Cancer Symposium; 2011.

doi:10.1186/1475-2867-13-53

Cite this article as: Jiang et al:: BAD overexpression inhibits cell growth and induces apoptosis via mitochondrial-dependent pathway in nonsmall cell lung cancer. Cancer Cell International 2013 13:53.

Submit your next manuscript to BioMed Central and take full advantage of:

- Convenient online submission

- Thorough peer review

- No space constraints or color figure charges

- Immediate publication on acceptance

- Inclusion in PubMed, CAS, Scopus and Google Scholar

- Research which is freely available for redistribution

Submit your manuscript at www.biomedcentral.com/submit
( ) Biomed Central 